\title{
GCU
}

Glasgow Caledonian

University

University for the Common Good

\section{Never try and face the journey alone: exploring the face-to-face advocacy needs of fuel poor householders in the United Kingdom}

Baker, Keith J.; Mould, Ronald; Stewart, Fraser; Restrick, Scott; Melone, Helen; Atterson, Barbara

Published in:

Energy Research and Social Science

DOI:

10.1016/j.erss.2019.01.009

Publication date:

2019

Document Version

Author accepted manuscript

Link to publication in ResearchOnline

Citation for published version (Harvard):

Baker, KJ, Mould, R, Stewart, F, Restrick, S, Melone, H \& Atterson, B 2019, 'Never try and face the journey alone: exploring the face-to-face advocacy needs of fuel poor householders in the United Kingdom', Energy Research and Social Science, vol. 51, pp. 210-219. https://doi.org/10.1016/j.erss.2019.01.009

\section{General rights}

Copyright and moral rights for the publications made accessible in the public portal are retained by the authors and/or other copyright owners and it is a condition of accessing publications that users recognise and abide by the legal requirements associated with these rights.

Take down policy

If you believe that this document breaches copyright please view our takedown policy at https://edshare.gcu.ac.uk/id/eprint/5179 for details of how to contact us. 


\title{
Never try and face the journey alone: Exploring the face-to-face advocacy needs of fuel poor householders in the United Kingdom
}

\author{
Keith J. Baker ${ }^{\mathrm{a}, \mathrm{e}}$, Ronald Mould ${ }^{\mathrm{a}, \mathrm{b}}$, Fraser Stewart ${ }^{\mathrm{c}}$, Scott Restrick ${ }^{\mathrm{d}}$, Helen Melone ${ }^{\mathrm{d}}$, Barbara \\ Atterson $^{\mathrm{d}}$ \\ ${ }^{\text {a }}$ School of Computing, Engineering and the Built Environment, Glasgow Caledonian \\ University, Cowcaddens Road, Glasgow, G4 0BA, UK \\ ${ }^{\mathrm{b}}$ Property and Facilities Management, Resources, The City of Edinburgh Council, Level 1.4, \\ Waverley Court, 4 East Market Street, Edinburgh, EH8 8BG \\ c 30 North Fort Street, Edinburgh, EH6 4HD \\ ${ }^{d}$ Energy Action Scotland, Suite 4a Ingram House, 227 Ingram Street, Glasgow, G1 1DA, UK \\ ${ }^{\text {e }}$ Corresponding author: T. +44 (0) 7884 125540, E. keith.baker@ gcu.ac.uk
}

\begin{abstract}
The Scottish Government's recent review of its definition of fuel poverty has increased the focus on how best to deliver support to the most vulnerable fuel poor householders. Previously we have argued that this requires a greater emphasis on delivering face-to-face and in-home energy advocacy services however, we have also noted the need for further research to inform policy in this area. This paper presents findings from two related studies to elucidate our understanding of the energy advocacy needs of vulnerable householders. The first is a quantitative analysis of the types of support provided to vulnerable householders in Renfrewshire, which is contiguous with Greater Glasgow. The second is a qualitative study using semi-structured interviews with clients accessing energy advocacy services provided by South Seeds, a charity serving the Glasgow Southside community, conducted as part of a wider evaluation of the organisation. These serve to illustrate that often the support sought is for advice that must be delivered face-to-face and in-home, supporting previous studies that show the provision of advice by telephone and online is often insufficient for meeting the needs of vulnerable householders.
\end{abstract}

\section{Keywords}

Fuel poverty, Vulnerable, Energy, Advocacy, Support

\author{
Abbreviations \\ DNO - Distribution Network Operator \\ COPD - Chronic Obstructive Pulmonary Disease \\ EESH - (Scottish) Energy Efficiency Standard for Social Housing \\ EPC - Energy Performance Certificate
}




\author{
HES - Home Energy Scotland \\ LIHC - Low income, high costs \\ SEEP - Scotland's Energy Efficiency Programme \\ WHD - Warm Home Discount
}

\title{
1. Introduction
}

Fuel poverty in Scotland is currently defined by a Boardman-based metric that classifies a household as being in fuel poverty if more than $10 \%$ of household income, including benefits and before any deductions, is required to maintain a heating regime in line with the World Health Organisation's guidance $[1,2,3,4]$. However, this definition is now under review, and the revised definition is expected to include vulnerability as a distinction between those who should genuinely be considered as fuel poor, and the small proportion who simply have high energy costs [5]. This distinction can also be applied to the condition of energy poverty [6].

The Scottish Government's efforts to tackle both energy efficiency and fuel poverty are currently administered largely through Scotland's Energy Efficiency Programme (SEEP) [7], which delivers advice and support through a combination of national and locally-based schemes, in partnership with public, private and third sector organisations. The cornerstone of SEEP is the national Home Energy Scotland (HES) telephone helpline and website, supported by a limited number of Community Liaison Officers delivering face-to-face support at a multi-authority level, which is intended to deliver all these schemes and services under a unified brand [8]. However, whilst this policy approach may be sufficient for supporting energy-aware householders to become more energy efficient, the reliance on using centralised (remote) resources may be a barrier to access for the most vulnerable, and therefore insufficient for addressing the needs of the most in need.

A further contention here, based on our previous work [9,10], is that the Scottish Government's policies on fuel poverty have been too orientated around what it, and its partner organisations, have the capacity to deliver, rather than necessarily what is needed. Whilst we, and the Scottish Government, acknowledge the difficulties of placing an economic valuation on additional benefits [11], we argue that a greater understanding of the needs of vulnerable householders would itself be sufficient to merit a change of policy direction.

In this paper we explore the needs of fuel poor and otherwise vulnerable householders by presenting two new studies, one of which was conducted as part of a wider evaluation [12]. The findings are further supported by evidence gathered for a research project on understanding the needs of householders with electric heating, conducted in parallel with the other research presented here [13]. Although this new evidence is largely limited to householders in urban and peri-urban areas there are clear parallels with evidence from rural and island areas [14], and from international studies $[15,16]$.

The paper builds directly on our previous paper in this journal on reconceptualising fuel poverty as a highly complex and predominantly social condition, but one which is nevertheless modellable given a sufficiently holistic scoping of information $[17,18]$. This is consistent with the work of Berry et al. [19] on the development of a composite indicator for vulnerability to transport fuel poverty. As recognised by Dubois and Meyer [20], the different social conditions that underlie the extent to which fuel poverty is a national / general problem or one more common amongst specific social groups, even within the European Union, makes it difficult to develop a unified approach to tackling the problem across all countries. Exploring these is beyond the scope of this paper. 
The findings from the research are necessarily constrained by the need to address the Scottish context and may be generalised to any country where domestic heating is a significant contributor to household expenditure on energy. Furthermore, the findings for 'what works' when delivering support to fuel poor and otherwise vulnerable households may have some generalisability across countries with similar cultures and social norms.

\section{Background}

With the exception of England, which adopted a 'low income - high costs' (LIHC) definition in 2013 [21], the UK defines a household as being fuel poor according to the ' $10 \%$ of income' (Boardmanbased) definition, with minor variations between Scotland, Wales and Northern Ireland [22]. We and other authors have previously argued in favour of the benefits of the Boardman definition, and against the adoption of a LIHC definition [23,24]; but we have also highlighted the limitations of the Boardman definition and proposed the basis for a reconceptualisation that includes a risk-based assessment of householder vulnerability [17,18].

In line with our previous work $[17,18]$ we use the term 'fuel poor and otherwise vulnerable' to mean those householders who fall under the Scottish / Boardman definition of fuel poverty and / or those who exhibit one or more characteristics that would broadly identify them as being vulnerable to fuel poverty and its impacts. This is based on our understanding that fuel poverty can often be both a result of and an influence on other aspects of vulnerability, and cannot be effectively addressed in isolation from these factors $[17,18]$. It follows from this that, beyond the limitations of the two studies, we are deliberately not proscriptive of the definition of 'vulnerable'. We also note that the development of a Scotland-specific definition of vulnerability was one of the recommendations of the recent academic panel review [5].

One important consequence of the definition being limited to a technical and income-based assessment is that the designing of mitigation programmes in the UK has traditionally focused on a 'fabric first' approach. This has resulted in resources being prioritised towards low-cost technical solutions such as insulation, replacement glazing, draught-proofing, and boiler replacements [25]. These are attractive to policymakers as they have theoretical energy, emissions, and cost-saving benefits that can (in theory) be modelled, quantified and reported. Though the accuracy of these energy models has been widely questioned, particularly when applied to the Scottish housing stock and climate $[26,27,28,29,30,31,32]$. These limitations have long been understood by building scientists [33,34], but less so by policymakers [35].

A related problem is the prevalence of the use of archetypes to group both householders and dwellings according to basic, rigid criteria (e.g. dwelling type, household composition). Standard sets of interventions are then assigned to these archetypes based on what policymakers understand from the (modelled) figures will be necessary to meet the needs of householders in each grouping $[13,17,18,36]$. This approach is attractive to government because it leads to simple decision-making trees for determining eligibility for support that can be delivered centrally, and so reduce costs whilst being able to report engagement with large numbers of householders [37].

However, each one of these simplifications in decision-making and delivery distances vulnerable householders from accessing support [13]. We know, for example, that the more steps householders need to take from initial contact to the completion of an intervention the less likely they are to complete the 'customer journey' [38]. We also know that remote provision of support by telephone and online services poses barriers to access by vulnerable groups such as older people and those with physical or mental impairments [16,39]. 
A supplementary point that merits recognising here is that the term 'customer journey' is in common usage in Scottish policy however, we would prefer to see 'client' used as a more accurate reflection of the nature of the relationship between householders and delivery bodies. The reason for this is how this use of terminology frames the relationship between the householder and the service provider. A customer is defined as "someone who buys goods or services from a shop or business" [40] whereas a client is defined as "a person or organisation using the services of a lawyer or other professional person or company", and also as "a person being dealt with by social or medical services" [41]. The latter definition more closely reflects the characteristics of fuel poor and otherwise vulnerable householders as regards their relationships with their service providers, who often act as their intermediaries.

In light of this it is perhaps not surprising that the term 'hard-to-reach' has entered the policy lexicon $[13,17,18]$, which in Scotland is defined by a number of 'excluded groups' who tend to be underrepresented in participatory activities, specifically: those on low incomes; members of black and ethnic minority groups; disabled people; young people; homeless people; members of faith communities; members of rural communities; and those in full time employment $[42,43,44]$. This has parallels with the equivalent technical term for buildings, 'hard-to-treat' [45]. Yet the intention of this latter report was not to demonstrate that properties classified as 'hard-to-treat' are particularly technically difficult or costly to remediate, indeed quite the opposite, but to point to a number of largely socio-economic factors, such as the high prevalence of multiple-occupancy and multipletenure buildings, which pose specific non-technical barriers to delivering 'whole house' packages of solutions. That is to say, we argued that in reality 'hard-to-treat' properties represent market, policy and legislative failures, not technical barriers. 'Hard-to-reach', simply by its emergence in the policy lexicon, is a tacit admission of policy failures; Stearn (2016) draws the same conclusion when it comes to 'vulnerable' householders, "Consumer vulnerability cannot simply be seen as consumers' failure to engage with the market when markets are failing to engage with consumers" [46].

The definition of 'vulnerable' itself is open to interpretation. In Scottish policy we tend to associate it with a household(er) meeting one or more of the criteria used for targeting and apportioning support. However, these blunt criteria contrast with the broad definition set by the International Standards Organisation - "a group of individuals who share one or several characteristics that are the basis of discrimination or adverse social, economic, cultural, political or health circumstances, and that cause them to lack the means to achieve their rights or otherwise enjoy equal opportunities" [47].

The use of such broad-brush labels, be they positive or negative, is problematic for developing more nuanced insights into these groups due to phenomena known as 'verbal overshadowing' [48] and 'unconscious transference' [49]. To date, much of the evidence of these effects comes from the fields of psychology and criminology, where it has been found to explain how witnesses to a crime may mis-identify the suspect or a judge and jury may reach the wrong conclusion, even where there is no direct evidence of bias (e.g. racial bias) on behalf of the participants.

As regards developing policy and support packages for householders, verbally labelling individuals and grouping them into a limited number of simplistic archetypes (for example see [36]) both excludes other information and introduces potential subconscious contextual and cultural biases. For example, labelling a householder as 'disabled' says nothing about the type or severity of that disability (or disabilities), if and how this affects their household energy behaviours and capacity to modify them, the support they need (or don't) to adopt lower energy behaviours, and therefore how responsive they are likely to be to different engagement routes. This use of such archetypes is particularly counter-productive for supporting vulnerable householders with complex circumstances and support needs $[17,18,50]$. 
In this context, the focus on developing a better understanding of vulnerability as part of the Scottish Government's academic panel review of the definition [5] is a positive policy development, if the recommendations are taken up. However, the benefits of this will not be fully realised if policies retain a reliance on simplified classifications of vulnerability currently used for apportioning support, which have been found to be insufficient for understanding and addressing the needs of the vulnerable and fuel poor $[17,18,51]$.

Given the evidence that the provision of advice by staff working remotely (by phone, online, etc) creates barriers to vulnerable householders accessing these services, we sought to use two opportunities to access data / information on households accessing energy advocacy services to explore what support is being sought, and why clients are choosing to access face-to-face and in-home support. What evidence do we have on the needs of the vulnerable fuel poor, and how and why are current policies failing them?

\section{Methods}

Quantitative and qualitative data can be used to describe complementary aspects of fuel poverty, and so the triangulation of this data enables us to build a more complete understanding of the impacts on householders. This mixed-method approach enables a more effective elucidation of the lives, challenges and barriers that the fuel poor face and documents how they may be excluded from services, and society, through circumstances or other drivers [51,52,53,54,55,56].

Definitions of vulnerability are adopted into policies as qualifying criteria for enhanced funding [57] and are therefore important in defining the nature of responses to mitigating fuel poverty from Government and their agencies. We have previously argued that the current vulnerability classifications are an over simplification of a complex scenario $[17,18]$ which itself is an aspect of poverty (in general) being a complex condition [58]. Therefore, we have sought to both quantify the types of support being accessed by vulnerable householders, and to illustrate the benefits of enabling them to access face-to-face support. Further research is intended to develop a holistic economic valuation of this support but this is beyond the scope of this paper.

\subsection{The role of 'trusted intermediaries'}

The studies reported here emphasise the role of 'trusted intermediaries' in both delivering support to fuel poor and otherwise vulnerable householders, and elucidating more robust, and candid, evidence from them. For the Renfrewshire study this is limited to ensuring confidence in the validity of the data however, for the South Seeds study this was fundamental to the design and delivery of the evaluation. The approach here is firmly rooted in the rationale that accessing and understanding the knowledge held by such trusted intermediaries is essential as part of developing a more holistic conceptualisation of these householders and their needs $[17,18]$.

We use the term 'emic' to denote defining or relating to cultural phenomena as viewed from perspective of someone within that society, as opposed to an observer outwith the society (termed 'etic') $[17,18,59,60]$. By virtue of being embedded in the community, and trusted by residents, the Renfrewshire Energy Advocates and the South Seeds staff are able to offer insights that 'outsiders' would have greater difficulty revealing. This means as researchers we are able to place particular value and trust in what they have reported. In contrast, inquiries from the outside, that is etic research, may elucidate an understanding of the drivers for developments and actions through questionnaires, interviews and observations however, these are subject to the interpretation of the researchers $[61,62]$. 
Emic research from the inside of groups is more able to develop a more empathetic understanding of the study groups' drivers and how they think of themselves [63]. We recognise the tensions between and the value in both approaches [64]. Our research adopts an emic approach to enable a better understanding of the study group and provide the evidence to challenge established thinking.

\section{Materials}

This paper draws on evidence from two service providers, one local authority and one communitybased organisation, supporting fuel poor and otherwise vulnerable householders in the geographically contiguous areas of Glasgow and Renfrewshire. Whilst Glasgow is an entirely urban area that extends into Renfrewshire, the latter region also encompasses rural and island populations. The majority of the householders captured by the studies are council or housing association tenants, although it was not possible to determine a precise figure for this.

The Renfrewshire Council service is offered universally to all residents without prejudice but focuses on the vulnerable and fuel poor through referral partnerships. All the contacts recorded in the database are face-to-face meetings or home visits, usually following an initial phone call to arrange a time. A very small number of enquiries are dealt with in that initial phone call $(<5 \%)$ and all referrals from other services automatically trigger face-to-face or home visits. South Seeds services are accessible to all householders in the area of south Glasgow served by the organisation and the study was designed to include a broad range of clients typical of those helped by the organisation. The householders who would not typically be classified as vulnerable provide useful contextual evidence on why they sought out support from the organisation and the benefits they received. As for our previous studies [14,23] household records were compiled by trusted intermediaries $[65,66]$, subject to the provisions and restrictions of the UK's Data Protection Act 1998 [67] and Welfare Reform Act (as amended 2012) [68]. A sample of 2007 records gathered from householders in Renfrewshire who first accessed the service between August 2014 and December 2016 were interrogated to quantify the different forms of support being sought.

This dataset includes: the name of the service supporting the householder; the name of the Advocate; the scheme (if any) that the client was referred from; the dates of the clients accessing the support, including dates of home visits and follow-ups; whether the client was successfully engaged by the Advocate, and if not the reasons for this; the household address (anonymised to full postcode); the number and age of household occupants; tenure; figures for electricity and gas costs, consumption before and after accessing support, and the resulting cost and $\mathrm{CO}_{2}$ savings; householder eligibility for different support options; details of actions taken - measures installed, debt written off, etc; and in some cases details of household finances (income, debt). Where records are sufficiently complete these were used to calculate additional figures for the percentage of income spent on fuel (i.e. the fuel poverty statistic) and financial savings expressed as a proportion of income. These analyses were undertaken by one of the authors as part of their employment at the council and in accordance with the access restrictions placed on the data by the council.

As a self-selecting sample (by virtue of accessing the service) there is a strong and intended bias towards capturing householders classified as fuel poor under the current Scottish definition however, in light of the timing and primary aim of this work, we did not seek to exclusively capture 'fuel poor' or 'vulnerable' householders. A further caveat here is that both these terms are subjective, invariably defined by blunt thresholds, and defined differently within policy documents and academic literature, and so for the purposes of this paper it is reasonable to apply those terms as broadly as possible. 
Further limitations here are the geographical focus, which is intentionally limited to the south of the Greater Glasgow conurbation and its neighboring peri-urban and rural areas to enable comparability between the findings. This, however, does not restrict the generalisability of the findings to other parts of mainland Scotland, and to a lesser extent to other comparable countries with similar social conditions and measures of fuel poverty. A further restriction on comparability is that detailed datasets of personal information on householders are generally difficult for researchers to access, and in this case access to the raw data was restricted to the council's secure network.

These quantitative findings are compared and contrasted with the results of 11 interviews with clients at South Seeds [12] a community-based energy advocacy service based in Glasgow Southside, which is geographically contiguous with urban Renfrewshire. The interviews were conducted as part of an independent evaluation commissioned by South Seeds, with the interviews conducted by the authors at South Seeds' office. The interviews were arranged by South Seeds' staff, and this trust between the staff and their clients enabled us to gather information from individuals who would normally be unlikely to engage with academic research. As noted in the evaluation, the South Seeds office (which has a very visible shop front on a high street) is notable for being a welcoming environment for vulnerable clients.

As for the Renfrewshire sample, the clients interviewed were selected for the purposes of understanding the benefits of face-to-face support, in this case by capturing clients accessing the whole range of services provided by South Seeds, and so was not to limited to fuel poor householders. Interviews were conducted using the semi-structured interview guide available in the final report, and all participants gave permission for the interviews to be recorded. This still poses a limitation, albeit a minor one, on the degree of disclosure of personal or sensitive information to the researchers, as opposed to training South Seeds staff to conduct the interviews themselves. As well as being significantly costlier and more time-consuming this would naturally have been a conflict of purpose with conducting the evaluation of the service.

\section{Results}

\subsection{Analysis of the Renfrewshire energy advocacy data}

Table 1 shows the key statistics for household occupancy and tenure (where the records are complete). Table 2 and Figures 1 and 2 show the raw numbers for the different categories of support provided to clients by the Advocates through the three support schemes operated by the council, and the percentages of clients accessing each scheme receiving each type of support. Note that the percentages are not cumulative as any client may receive more than one, or no, type of support, and clients may be eligible for support from more than one scheme. The three schemes are 'Families First,' which engages with just coping families with children at primary school; C4R, which engages with housing association tenants; and Renfrewshire Wide, which is open to all other residents in the Renfrewshire area.

The categories of support delivered are as follows. Energy advice covers general advice on understanding energy bills, measures that could be installed, simple behaviour changes, etc, and usually involves the completion of a Home Energy Check. The Warm Homes Discount is a UK-wide scheme to provide financial support for energy bills to older and vulnerable householders. The Priority Services Register is managed by the energy distribution network operators (DNOs) and energy supply companies to enable customers classified as elderly and vulnerable to be prioritised for support in the event of a disruption to their energy supply. Demonstration and installation of central heating and the two categories for changing meters are self-explanatory. Support for failing to pay 
fuel bills commonly involves negotiating with the supplier to write-off or agree a management plan for repaying debt, but may include other forms of financial support. Similarly, arranging for a gas supply to be uncapped may also require the Advocate to contact the supplier or Housing Association on the clients' behalf. Price comparisons are conducted using the council's preferred online comparison tool, and the client may then go on to arrange a switch themselves, whereas supplier switching means the Advocate has acted on behalf of the customer to arrange this.

Note that in the cases of demonstrating heating and those where an Advocate has to act as the de-facto legal representative of the client when dealing with an energy supplier (e.g. arranging for debt to be managed or written off, uncapping supplies, changing meters) the support must be delivered face-toface, since the energy supplier may only agree for the Advocate to negotiate if the client is physically present with them.

Table 1 - Household occupancy and tenure of clients accessing council services

\begin{tabular}{|c|c|c|c|}
\hline Household Occupancy & $\begin{array}{l}\text { Number of complete } \\
\text { records }\end{array}$ & $\mathbf{N}$ & $\begin{array}{r}\% \text { of } \\
\text { complete } \\
\text { records }\end{array}$ \\
\hline Single occupant households & 1316 & 669 & $50.84 \%$ \\
\hline Households with children & 1316 & 476 & $36.17 \%$ \\
\hline Single parent households & 1316 & 299 & $22.72 \%$ \\
\hline $\begin{array}{l}\text { Households with one or more occupants } \\
\text { over } 60 \text { years old }\end{array}$ & 1316 & 243 & $18.47 \%$ \\
\hline Household Tenure & $\begin{array}{l}\text { Number of complete } \\
\text { records }\end{array}$ & $\mathbf{N}$ & $\begin{array}{r}\% \text { of } \\
\text { complete } \\
\text { records }\end{array}$ \\
\hline Owner-occupied properties & 1645 & 129 & $7.84 \%$ \\
\hline Privately rented properties & 1645 & 127 & $7.72 \%$ \\
\hline Council properties & 1645 & 1089 & $66.20 \%$ \\
\hline Housing Association properties & 1645 & 300 & $18.24 \%$ \\
\hline
\end{tabular}


Table 2 - Types of support provided by Renfrewshire Energy Advocates across three support schemes: Numbers and percentages of the total number of households referred accessing different types of support

\begin{tabular}{|c|c|c|c|c|c|c|c|}
\hline Support Scheme & Families Fir & & Renfrewsh & Wide & C4R & & Total \\
\hline Type of Support & $\mathbf{N}$ & $\%$ & $\mathbf{N}$ & $\%$ & $\mathbf{N}$ & $\%$ & $\mathbf{N}$ \\
\hline Energy advice & 329 & $68.40 \%$ & 847 & $61.42 \%$ & 145 & $98.64 \%$ & 1321 \\
\hline $\begin{array}{l}\text { Application of the } \\
\text { Warm Homes } \\
\text { Discount }\end{array}$ & 176 & $36.59 \%$ & 319 & $23.13 \%$ & 40 & $27.21 \%$ & 535 \\
\hline $\begin{array}{l}\text { Placement on the } \\
\text { Priority Register }\end{array}$ & 116 & $24.12 \%$ & 248 & $17.98 \%$ & 38 & $25.85 \%$ & 402 \\
\hline $\begin{array}{l}\text { Demonstration of } \\
\text { Central Heating }\end{array}$ & 309 & $64.24 \%$ & 714 & $51.78 \%$ & 136 & $92.52 \%$ & 1159 \\
\hline $\begin{array}{l}\text { Installation of } \\
\text { new Central } \\
\text { Heating }\end{array}$ & 9 & $1.87 \%$ & 39 & $2.83 \%$ & 1 & $0.68 \%$ & 49 \\
\hline $\begin{array}{l}\text { Support for } \\
\text { failing to pay } \\
\text { energy bills }\end{array}$ & 25 & $5.20 \%$ & 106 & $7.69 \%$ & 13 & $8.84 \%$ & 144 \\
\hline $\begin{array}{l}\text { Switching } \\
\text { household to a } \\
\text { credit meter }\end{array}$ & 10 & $2.08 \%$ & 17 & $1.23 \%$ & 2 & $1.36 \%$ & 29 \\
\hline $\begin{array}{l}\text { Change of energy } \\
\text { meter }\end{array}$ & 53 & $11.02 \%$ & 69 & $5.00 \%$ & 8 & $5.44 \%$ & 130 \\
\hline Gas uncapped & 11 & $2.29 \%$ & 49 & $3.55 \%$ & 3 & $2.04 \%$ & 63 \\
\hline Price comparison & 71 & $14.76 \%$ & 83 & $6.02 \%$ & 13 & $8.84 \%$ & 167 \\
\hline Supplier switch & 80 & $16.63 \%$ & 59 & $4.28 \%$ & 9 & $6.12 \%$ & 148 \\
\hline $\begin{array}{l}\text { Total number of } \\
\text { actions }\end{array}$ & 860 & N/A & 2550 & N/A & 408 & N/A & 4147 \\
\hline $\begin{array}{l}\text { Total number of } \\
\text { clients }\end{array}$ & 481 & N/A & 1379 & N/A & 147 & N/A & 2007 \\
\hline
\end{tabular}




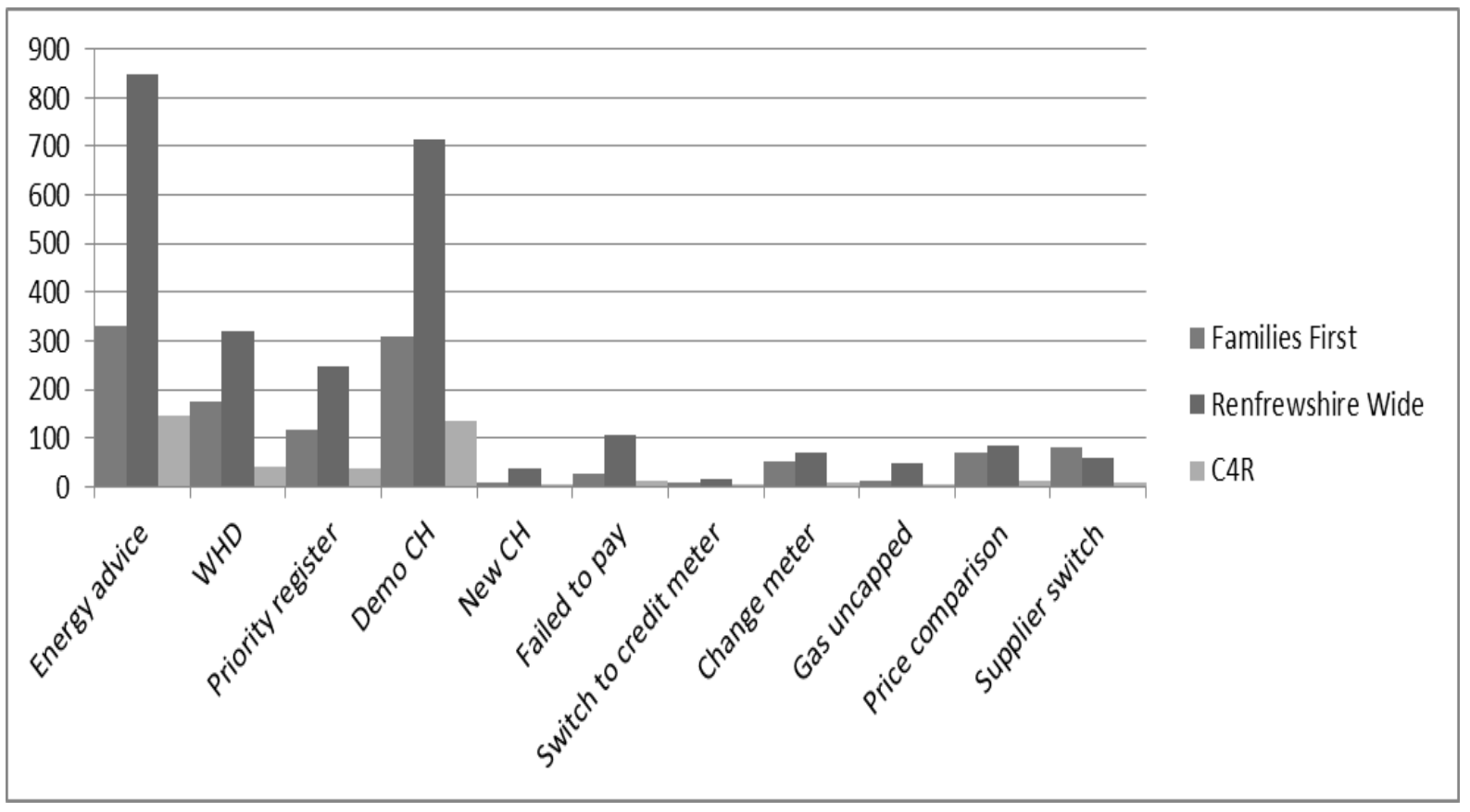

Figure 1 - Type of Support provided by Renfrewshire Energy Advocates, by scheme, raw numbers

Abbreviations: WHD - Warm Home Discount; $\mathrm{CH}$ - Central Heating

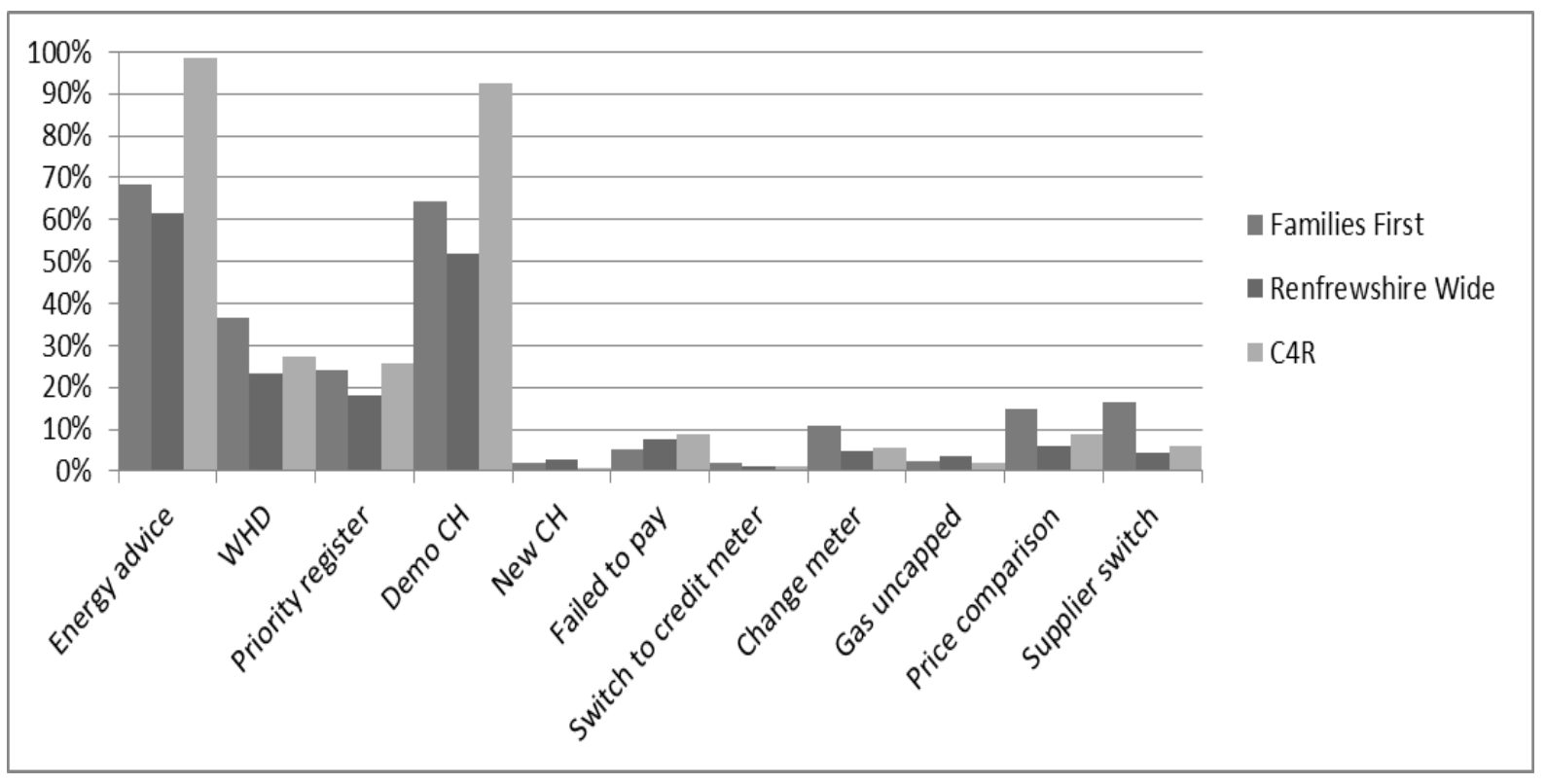

Figure 2 - Type of Support provided by Renfrewshire Energy Advocates, by scheme, by percentage

Abbreviations: WHD - Warm Home Discount; $\mathrm{CH}$ - Central Heating

The figures for household occupancy (where known) show the percentage of single person households accessing support is notably above the figure of one third of single person households recorded by the last Scottish Census, the most robust dataset available for national figures [69]. The percentage of 
single parent households is above the national average of $11 \%$, and the percentage of households with children is almost half the national average of $60 \%$. The figure for households with at least one person over 60 is not comparable as the Census defines an 'elderly' person as being 65 years old or over. The figures for tenure naturally reflect the nature of the dataset (the overall proportion of owner-occupied households in Scotland is $\sim 60 \%$ ). Due to regular maintenance regimes and the requirement to meet the Scottish Energy Efficiency Standard for Social Housing (EESSH) [70], the energy efficiency of housing owned by local authorities and housing associations is generally higher than for owneroccupied and privately-rented stock [71].

The first notable finding from the breakdown of types of support provided is the number of clients requiring a demonstration of how to use their central heating. This service, which requires a home visit, was delivered to over half of the clients in the dataset and accounts for $28 \%$ of the total number of actions. Council services are provided face-to-face and in-home wherever possible, so it is more difficult to ascertain a specific figure for the number of households for which the actions necessitate face-to-face contact as the dataset doesn't specifically note those cases where the advocate has had to act as a legal representative for the client (i.e. where the advisor must be physically present).

However, by adding the figures for uncapping gas supplies (which usually requires this) and support for failing to pay (where the advocate is invariably required to mediate between the client and their energy supplier) we can reasonably conclude that a minimum of $68 \%$ of 'client journeys' and $33 \%$ of individual actions required some form of face-to-face contact.

However, these raw figures alone fail to capture the whole picture and the added value of providing face-to-face and in-home advice. For example, the general category of 'energy advice' includes a number of activities (e.g. conducting home energy checks) that are generally (but not always) conducted in-home. Furthermore, face-to-face contact is more effective for countering the problem of 'presentation', where the root cause(s) of a client's problem may not be the issue(s) they are initially seeking support for [16], and in-home visits may uncover support needs (e.g. for technical problems, behaviour changes, understanding energy bills, mental health issues, etc) that would not be apparent to an advisor working remotely.

The nature of face-to-face services are that they meet the immediate and on-going needs of the clients whilst maximising the use of every contact with a client. As such, and within the scope of the available resources, face-to-face service staff are able offer a wide range of services, which may be not directly related to the reasons for the initial call out. For example, taking a client to a hospital or doctor's, or issuing a foodbank voucher. The next section explores this issue further.

\subsection{Results from the South Seeds interviews}

For this study, interviews were conducted with eleven clients, as well as South Seeds' Senior Energy Officer and a community support worker from a local housing association that refers clients to the organisation. The latter two interviews and extended versions of these interviews can be found in the evaluation report [12].

\section{Interview 1}

The client was male, new to the area, with chronic obstructive pulmonary disease (COPD) and asthma that had been aggravated by living in a draughty flat. He reported that, as a result of practical help and advice, he had seen a noticeable reduction in his energy bills and felt more confident about managing them, and had modified his behaviour as a result of the support by not over-filling his kettle and cooking more efficiently (and more healthily) by using a steamer. 
This is an example of a client who, whilst having a health condition, was otherwise educated and ablebodied, and would not generally be considered as being vulnerable or 'hard to reach'. Nevertheless, he reported that he didn't like getting advice by phone or online for a number of reasons - getting phone calls at dinner time, and online advice being too generic and not providing answers to specific questions.

\section{Interview 2}

The client was a young woman with educational and mental health support needs who had been struggling with her energy bills. Part of this problem had been caused by her meter being set up incorrectly, which was resolved by the installation of a new meter following South Seeds' staff speaking to the supplier on her behalf. Staff also conducted a home energy audit; provided her with low energy light bulbs (having spotted old bulbs in her flat); helped her with her boiler settings, applying for the Warm Home Discount, understand her energy bills and switch to a cheaper tariff; and advised her on how a thermal curtain could be installed. She had been referred to South Seeds by her Welfare Rights Advisor [at the housing association] and was very keen to recommend the organisation to others.

She reported that wouldn't have been able to solve the issue with her boiler over the phone because it would have been very difficult to communicate the problem and understand what she needed to do to resolve it. She had also been to the supplier's office (which is in the local area) and had received some help from someone she knew from the local community, indicating that she had actively sought out face-to-face advice. Furthermore, as a result of receiving support she had been encouraged to get involved with South Seeds' allotment project. As is so often the case, this was an individual who, on paper, had complex support needs who benefitted significantly by having a known person to ask for help.

\section{Interview 3}

The client was a single mother of a school-age daughter who had been referred to South Seeds by the housing association due to an incorrectly-set meter. She had had difficulties with getting her supplier to resolve this, resulting in escalating energy costs, significant stress, a deterioration in her mental health, loss of benefits, and at one point being disconnected for a few days, meaning her daughter had to seek help in order to be able to do her homework. Staff resolved the issues with the meter and supplier, including getting compensation, showed her how to use trip switches, and helped her get the Warm Home Discount applied to her energy bills - including accompanying her to a pay point to explain how it worked.

This client was an example of someone whose degree of vulnerability changed significantly and rapidly due to factors out of her control. As a time-poor mum she didn't want to have to spend time visiting the library to access information online, and had benefitted significantly simply from the empathy of face-to-face advisors, who were able to quickly understand the causes of her problems and start addressing them from day one.

\section{Interview 4}

The client was an older man with high energy bills due to having old, inefficient storage heaters. Staff conducted a home energy assessment to help him understand his bills and helped him arrange for the storage heaters to be replaced with a gas central heating system (including securing a grant from the 
energy supplier), arrange for the Warm Home Discount to be applied to his bills, and installed low energy lightbulbs.

In theory, this was a client whose needs could have been met through the national HES helpline however, he commented that he had only thought to seek help because of passing South Seeds' office, and that the staff had been in and out of his house a lot. Thus demonstrating the value, and trust, many householders' place in face-to-face and in-home support.

\section{Interview 5}

This client was a young, able-bodied man in a skilled profession with a high (and technical) level of energy awareness. He had recently moved into a nearby flat and, having spotted the office, asked South Seeds to conduct an energy audit on it. He was given advice on options for standard energy efficiency upgrades, as well as draught-proofing options for a storm door, and had been loaned a smart meter which he reported he was making lots of use of and adjusting his energy behaviours.

However, the main problem identified by the audit was the single glazed sash and case windows, which he was remedying by installing secondary glazing, with support from South Seeds. Although he had contacted South Seeds first, he had also had contact with Home Energy Scotland as part of getting the windows replaced and reported a very unsatisfactory experience with them. He was also aware that having the property assessed for an Energy Performance Certificate (required for accessing funding) would recommend installing double glazing, which for technical / conservation reasons would not be appropriate for his property. The client had also engaged with South Seeds' other services, including the allotments project, and commented that he valued the community-based ethos of the organisation.

Although neither fuel poor nor vulnerable, this was an important example of both the individual nature of energy efficiency needs and of the benefits to community-building of locally-based, flexible support services.

\section{Interview 6}

The client was a middle-aged professional woman who had recently moved into the community and was a regular visitor to the office and actively involved with South Seeds' wider community activities (the allotments project and keep fit classes).

Staff had provided her with a wide range of support, including conducting an energy audit, providing her with a smart meter and advice on low energy behaviours and draught-proofing options, installing LED lightbulbs, and loaning her a thermal camera. She was also in the process of converting her flat to gas central heating, which she had initially found a daunting prospect, but she had been encouraged by examples of other people in the area who had gone through the process. She commented that the way this gave her confidence was a subtle thing, but it was important that she didn't feel talked down to or patronised.

She reported that she hadn't sought help from Home Energy Scotland or other organisations because she thought wouldn't see the same person each time, and would have had to fit within their parameters for receiving help; and also that she wouldn't seek help online because this provides onesided advice that isn't tailored to individual needs, and again the need to meet certain criteria to receive support. However, she did report engaging with South Seeds on Facebook, because of their more personal and community-based approach to working. 
This client was someone who would not be classed as vulnerable in any way, but by virtue of being new to the community had experienced feeling isolated and helped herself to make friends and find ways to help others, which is a key aim under the Scottish Government's community empowerment and social isolation agendas $[72,73]$.

\section{Interview 7}

The client was an unemployed woman who had lived locally for around 10 years in a housing association flat, and would be classified as vulnerable. A friend had recommended South Seeds to her for help with managing her energy bills because her energy supplier had recently increased her direct debit amount, but she was already familiar with the organisation because of the shop front.

South Seeds' staff had acted as advocates in her negotiations with her energy supplier, helped her apply for the Warm Home Discount, conducted an energy audit to help her understand her energy use, and provided advice on making standard energy efficiency improvements. Although she was unable to say how much this had saved her on her bills, she did report feeling more confident in managing her energy bills (we did not ask her directly if she was self-rationing, but this suspected by the staff and would explain this response).

The client was keen to stress the value of face-to-face support over telephone and online services, the reasons for this being the complexity of energy issues, which can be difficult to navigate and can have financial implications. South Seeds was able to understand in detail the situation and provide bespoke advice to try and resolve the problem by advocating on her behalf. She commented that she wished South Seeds could provide the full range of support services (e.g. the benefit checks needed for accessing financial support) as she felt other services aren't as client-oriented, well-developed, or located in the community.

\section{Interview 8}

This client was a young, single man, who had been living alone for only a short period of time. He was in debt with his energy bills, due to a failure to pay them. A friend had recommended South Seeds, and the shop front location had been a factor in him going to them for support.

Staff were able to advocate with the energy supplier on the client's behalf, so that his energy bills came down and his debts were starting to be repaid. They also conducted a home energy audit, resulting in him receiving a new boiler and LED lightbulbs, helped him provide meter readings to his supplier, and advised him on simple energy saving measures and behaviours. This was saving him around $£ 15$ per month on his energy bills, and he reported feeling more aware of his energy use at home and more confident in taking action himself.

The client was strongly of the view that face-to-face advice is central to getting help with energyrelated issues, which can be too complex to explain over the phone. For this client, it also allowed for trust and rapport to be built up which was key to him asking for help.

\section{Interview 9}

This client was a housing association tenant, with English as a second language, in considerable debt to his energy supplier. The housing association recommended South Seeds to him as a charity that could potentially help in getting his payments reduced and his debt paid off. He was extremely satisfied with South Seeds because they worked hard and fast to get his problems resolved. He reported lower energy bills and feeling confident in managing his energy costs and knowing his 
responsibilities. More importantly, this was a client who did report energy rationing, and who was now able to use his heating system more and improve his level of thermal comfort.

The value of face-to-face advice for this client was evident, particularly as language was a barrier to receiving advice on complex issues by phone. In addition, it was evident that being locally-based meant that this 'hard to reach' client was able to build up a trusting relationship with the staff.

\section{Interview 10}

The client was an owner-occupier with an asthmatic child, living in a basement flat, which she described as quite cold and draughty. The block is mixed-tenure with owner-occupier, private-rented sector and housing association residents, so classified as 'hard to treat'. She had approached South Seeds for help because of both her energy costs and the impact her living conditions were having on her child's health. She was aware of South Seeds as she worked for another community-based organisation in the area.

Staff had conducted a home energy audit and helped her install secondary glazing, and she was receiving on-going help with a metering issue. Although the latter problem had yet to be resolved she reported feeling more confident to be proactive in addressing energy-related issues in her property by taking simple steps to reduce her energy bills.

This was an example of a client who, whilst not having the capacity to absorb more complex technical information without some help, was highly motivated to save energy - both to improve her living conditions and help the environment. This meant she placed a particularly high value on the tailored and in-home nature of the support provided, which she reported as helping take her "to the next level" in what she was able to do with her home. She felt that the energy advice from other organisations, such as the Energy Saving Trust, tends to be "much flatter advice; it might be online or a very general leaflet, rather than the much more community-based individual help" [that South Seeds provide].

\section{Interview 11}

This client was a young, energy aware, owner-occupier, living in a top-floor tenement flat close to the office, who had found out about the organisation following their move to the shop front location.

Although already taking steps to reduce her energy bills, she had benefitted from an energy audit and other checks around the home, including having a home energy monitor in her home to help identify anything more that could be done.

She reported being happy that she had scored very well on the audit, and that it had identified other options for reducing her energy bills, such as replacing a number of inefficient appliances. She had also made use of South Seeds' guide to installing a bicycle storage rack in her flat (bicycle storage in tenement flats is a well-known barrier to encouraging cycling in Scotland and many of the other clients commented on this).

Although this was a client who was neither vulnerable nor suffering from high energy costs the support provided had still empowered her, and she reported feeling more confident about making decisions about energy use at her workplace as well as at home. Again, she put this down to being able to drop by the office for personalised, face-to-face advice.

\section{Summary}


In almost all of these cases the needs of the clients necessitated face-to-face / in-home contact, and all clients expressed a strong preference for this. There are three cases (Interviewees 4, 5 and 6) where the support for energy issues being sought could have been managed remotely, although in the case of Interviewee 5 this support had been accessed and had not been adequate for meeting the client's needs. However, even in these cases the additional benefits of face-to-face support for enabling clients to become more empowered, and in many cases to become integrated with their community, are clearly apparent. These benefits are realised through the personal rapport and trust that the advocates are able to develop with the clients, and this key theme runs through all the interviews.

\section{Discussion}

Throughout this paper we have deliberatively sought not to be proscriptive with the use of the term 'vulnerable' in relation to service users for the same reason Stearn (2016) [46] notes that this categorisation of energy consumers would be better reframed as the failure of measures to enable them to engage with the energy market (see Interviews 1,2,3,7,8 and 9). Ergo, the use of the term by policy makers and delivery bodies also frames the problem as one of clients having difficulties in engaging with support services, rather than the engagement methods used by those services being insufficient to engage effectively with them. By being proscriptive we would further open ourselves to the effects of verbal overshadowing and unconscious transference.

By considering the problem from the perspective of what types and forms of support are being accessed by 'vulnerable' householders we have shown that we can conclude, with confidence, that a large proportion of these 'client journeys' necessitate at least some element of face-to-face or in-home support however, the dataset would need a higher level of detail and completeness of records to put a precise figure on these numbers (for any definition of 'vulnerable'). One reason for this lack of granularity is the sheer administrative scale of the task of compiling this information for thousands of households served by three complementary schemes. Often, as was the case with the South Seeds interviews, this information is spread across digital and hard copy records, as well as the tacit knowledge [74] of the clients held by the advocates supporting them however, this latter form of knowledge is itself a benefit achieved from face-to-face support from staff known to the clients. A fundamental problem that underpins this, as recognised in our evaluation, is that community-based organisations exist in a state of constantly needing to secure new funding and so lack the resilience and capacity of the public sector to invest in developing integrated data management systems.

A further problem, which illustrates the possible futility of attributing many interventions to directly measurable outcomes, is how to reasonably categorise different forms of 'energy advice'. For example, Home Energy Checks may identify the need for technical measures which, when installed, deliver benefits that are commonly assumed to be modellable with some degree of accuracy, but they also commonly identify options for behavioural changes. We have cited evidence as to why this is a poor evidence base on which to base policy decisions, and noted that this belief in the validity of modelling has itself driven the 'fabric first' policy approach to tackling fuel poverty. However, even if the far more complex problem of accurately modelling the impacts of minor behavioural changes could be overcome by intensive 'house in a lab' studies, this is not the same problem as attributing the benefits of such behaviour changes to reductions in individual household energy costs in the field due to factors such as the Hawthorne Effect [75] and the innate complexity of individual household energy behaviours.

The latter problem is further exacerbated amongst vulnerable householders with what local authorities commonly term as 'chaotic' lifestyles. Such households pose particular difficulties, including ethical issues, for engaging with research projects (e.g. Interviews 2 and 9). The South Seeds study shows that by working with trusted intermediaries it is possible to engage such householders with 
conventional interview-based research however, to date there remains a dearth of such studies, and the results presented here should not be considered as capturing anywhere near the whole picture of energy behaviours amongst these households. Further examples are given in our previous paper [17].

This means it is inherently difficult to treat householders as we do their homes and develop a 'folk first' strategy for tackling fuel poverty. In part, this is simply because we lack sufficient evidence to do so (we would argue that this also applies to buildings), but without a fundamental change in political thinking that recognises the limitations of using conventional social science-based approaches for addressing complex policy problems [76] such a strategy would likely be still be built on archetypes and broad-brush assumptions. Nevertheless, our on-going research is showing how, through applying methods from complexity science and using existing data, it is possible to rethink policy approaches to enable the delivery of 'folk first' solutions [18].

Another option would be to consider the problem purely in terms of economic costs and benefits, apportion public funding according to demand, and be far less proscriptive about what it may be used for. Using the Renfrewshire data and that held by other local authorities and delivery bodies we could begin to place a value on the cost of supporting fuel poor and otherwise vulnerable householders. At a basic level this would be the staff and resource costs of the support services, adjusted for an estimate of the number of households they were unable to support with the resources available to them. However, such a blunt measure of costs and benefits to energy savings (where they can be attributed) would not capture their wider costs and benefits to individuals, support organisations, the environment, the economy, and society [10,11], as illustrated by the South Seeds study. Furthermore, such a limited cost-based valuation risks disadvantaging efforts to encourage greater investment in tackling fuel poverty, as one of many issues that place competing demands on public funding and resources.

However, we can still point to what is needed by householders, and what works for engaging the 'hard to reach', and essentially say 'we need more of that'. In a recent study of home energy advice visits Reeves [77] identifies a number of qualities of successful delivery approaches:

- A long-term service with strong local recognition

- Delivery by or in close partnership with a local authority

- Using a multi-partner referral network to connect vulnerable households with support

- Using targeted mail-outs to vulnerable demographic groups

The study also found that housing a local fuel poverty support service within a local authority offers many benefits in terms of access to data on local households and linkages with partner organisations. Similarly, the model of a local authority commissioning this service from a specialist voluntary sector organisation appears effective, and could bring the benefits of dedicated expertise and a strong independent brand.

More specifically, Boardman and Darby [39] conclude that the delivery of effective advice to the disadvantaged has some or all of the following characteristics:

- Seeking out potential clients and offering a Freephone service

- Offering home visits where needed

- Having information on grants from all sources and assisting customers in applying for them

- Having well-trained and experienced staff

- Using bills as a source of information and feedback 
- Viewing advice as an interactive process between householder and adviser, in which dialogue is necessary and productive

- Networking with trusted agencies who are responsible for visiting people in their homes and giving assistance, and training such frontline workers

- Providing follow-up visits or phone calls as needed

- Taking into account the fact that many customers have difficulty with seeing, hearing, mobility, literacy and numeracy

Further evidence comes from a 2005 study that found that minimising the number of contacts needed between clients and service providers, and minimising the number of service providers involved in delivering an intervention, is critical to minimising the drop-out rates from support schemes, particularly amongst the most vulnerable [78]. All the evidence here is consistent with our own work and the supporting studies referenced in this paper and, to a greater or lesser extent, reflects the actual working practices of public and community-based organisations, yet the benefits and co-benefits of these remain poorly recognised and accounted for by policy makers in Scotland.

A corollary to this is the evidence for the benefits of 'opportunistic' approaches that capture householders at points in their lives where receiving support offers particular benefits $[79,80]$. Such trigger points include technical triggers such as changes of ownership, occupancy, or extending properties, as used effectively as part of the Residential Energy Conservation Ordinances (RECOs) used in parts of the USA [27,81] and also, more importantly, changes of personal circumstances that leave them particularly vulnerable to fuel poverty and its impacts. In the case of the latter, a further issue is the need to capture householders for whom this may only be temporary but whose well-being is at risk of falling into negative feedback loops if their problems cannot be addressed at their time of need [12]. Here again, personal contact at the right time may make the difference between whether or not a householder is captured by one or more of those negative feedback loops.

Finally, in order to close the evidence-policy loop, further research is needed to fully map and quantify the costs and benefits of such holistic 'folk first' approaches to tackling fuel poverty [18], which will necessarily require more public investment, and compare these with those of conventional techno-economic 'fabric first' approaches. Furthermore, there is also a need for policy makers to better understand the uncertainties inherent in the building models used as policy drivers. In Scotland, this need has now become particularly prescience in light of proposals under the draft Fuel Poverty (Target, Definition and Strategy) (Scotland) Bill [82], which will use energy performance ratings to mandate energy efficiency improvements to properties falling below a minimum standard. However, research by ourselves and many others illustrates both the technical uncertainties and socio-economic risks inherent in these proposals (as they stand) and proposes alternatives that would better serve the objectives of this policy agenda [83].

\section{Conclusion}

This paper illustrates both the need for, and benefits of, greater government investment in the provision of face-to-face and in-home advocacy and support services. The results from Renfrewshire show that, amongst vulnerable householders, there is a simple quantifiable argument for greater investment, while the findings from the South Seeds evaluation illustrate why decision makers should not be relying on these figures alone, and the need to consider the wider co-benefits [11] to both individual householders and the communities they live in.

Whilst it would be a hugely complex and potentially fruitless task to apportion person hours and costs to all the activities covered by this evidence and then apportion them to different modes of delivery 
(phone, online, face-to-face, in-home, etc) it is still clear that many either necessitate or are improved where they are delivered in person rather than remotely. Therefore, whilst the inherent, potentially irreducible, complexity of the issue makes attributing costs and benefits at least equally complex, it should still be reasonable for policymakers to consider the evidence of the need for, benefits, and cobenefits of providing face to face support to fuel poor and otherwise vulnerable householders, and conclude that 'we need more of that'.

\section{References}

[1] Scottish Executive, Scottish Fuel Poverty Statement 2002, Available at: http://www.gov.scot/Resource/Doc/46951/0031675.pdf (Last accessed 30 October 2017).

[2] B. Boardman, Fuel Poverty: From Cold Homes to Affordable Warmth, Belhaven Press, London, 1991.

[3] B. Boardman, Fuel poverty synthesis: lessons learnt, actions needed, Energy Policy 49, 2012, $143-148$.

[4] WHO, Indoor Environment: Health Aspects of Air Quality, Thermal Environment, Light and Noise, World Health Organisation, 1990.

[5] G. Bramley, S. Fitzpatrick, C. Liddell, J. Webb, A New Definition of Fuel Poverty in Scotland: A Review of Recent evidence, 2017, Available at: http://www.gov.scot/Publications/2017/11/7715 (Last accessed 17 January 2018).

[6] P. Pye, A. Dobbins, C. Baffert, J. Brajković,, I. Grgurev, R. De Miglio, P. Deane, P., Energy Poverty and Vulnerable Consumers in the Energy Sector across the EU: analysis of policies and measures: INSIGHT_E Policy Report for the European Commission, 2015.

[7] Scottish Government, Scotland's Energy Efficiency Programme, (Available at:

http://www.gov.scot/Topics/Business-Industry/Energy/Action/lowcarbon/LCITP/SEEP, 2017, (Last accessed 12 October 2017).

[8] Energy Saving Trust, Home Energy Scotland, 2017, Available at:

http://www.energysavingtrust.org.uk/scotland/home-energy-scotland (Last accessed 20 November 2017).

[9] K.J. Baker, R. Emmanuel, M. Phillipson, Review of the Energy Assistance Package.

Report for the Scottish Government, 2014, Available at: http://www.gov.scot/

Topics/Built-Environment/Housing/warmhomes/fuelpoverty/Energy-Assistance-

Package-Review-Report (Last accessed 13 March 2019).

[10] T. Maiden, K.J. Baker, A. Faulk, Taking the temperature: A Review of Energy Efficiency and Fuel Poverty Schemes in Scotland, Report for Citizens Advice Scotland by CAG Consultants, Glasgow Caledonian University, Andrew Faulk and the Energy Agency, 2016, Available at:

http://www.cas.org.uk/publications/takingtemperature (Last accessed 24 February 2018).

[11] A. Pridmore, A. Smith, K.J. Baker, C. Ahlgen, T. Williamson, Evidence Review of the Potential Wider Impacts of Climate Change Mitigation Options: Built Environment Sector, Report for the Scottish Government, 2017, Available at: http://www.gov.scot/Resource/0051/00513151.pdf (Last accessed 14 February 2018).

[12] K.J. Baker, F. \& Stewart, F., "Warm, friendly, reliable, and do what they say they do": An Evaluation of South Seeds' Energy Advocacy Services, 2017, Glasgow Caledonian University \& Dr Fraser Stewart, (December 2017).

[13] B. Atterson, S. Restrick, K.J. Baker, R. Mould, F. Stewart, H. Melone, H., 2018. Down to the Wire: Research Into Support and Advice Services for Households in Scotland Reliant on Electric Heating, 2018, Report for the Consumer Futures Unit, Citizens Advice Scotland, by Energy Actin Scotland, Glasgow Caledonian University, and Dr Fraser Stewart (October 2018).

[14] K.J. Baker, R. Mould, S. Restrick, Proiseact Spéird -The Spéird Project: Understanding Influences on Fuel Poverty in Rural and Island Scotland, Final Report for the Eaga Charitable Trust, November 2016, Available at: http://www.eagacharitabletrust.org/the-speird-project/ (Last accessed 24 February 2018).

[15] N. Cortis, I. Katz, R. Patulny, Engaging Hard-to-reach Families and Children, 2009, Occasional Paper No 26. Department of Families, Housing, Community Services and Indigenous Affairs, Australian Government. [16] S. Darby, Making sense of energy advice, (2003), in 'Time to Turn Down the Energy Demand', Proceedings of the European Council for an Energy-Efficient Economy Summer Study, 2003, 1217-1226.

[17] K.J. Baker, R. Mould, Documenting Fuel Poverty from the Householders' Perspective, Energy Res. Soc. Sci. 31, 2017, 21-31.

[18] K.J. Baker, R. Mould, S. Restrick. Rethink Fuel Poverty as a Complex Problem, 2018, Nature Energy, July 2018, DOI: https://doi.org/10.1038/s41560-018-0204-2.

[19] A. Berry, Y. Jouffe, N. Coulombel, C. Guivarch, Investigating Fuel Poverty in the Transport Sector: Toward a Composite Indicator of Vulnerability. Energy Res. Soc. Sci. 18, 2016, 7-20. 
[20] U. Dubois, H. Meyer, Energy affordability and energy inequality in Europe: Implications for policymaking. Energy Res. Soc. Sci, 18, 2016, 21-35.

[21] J. Hills, Getting the Measure of Fuel Poverty, Case Report 72, Department of Energy and Climate Change, UK, (March 2012).

[22] Trinomics, Selecting Indicators to Measure Energy Poverty. Final Report to the European Commission, (2016) (Rotterdam, 18th May 2016. Available at:

https://ec.europa.eu/energy/sites/ener/files/documents/Selecting\%20Indicators\%20to\%20Measure\%20Energy\% 20Poverty.pdf (Last accessed 20 January 2018).

[23] R. Mould, K.J. Baker, K.J., Uncovering hidden geographies and socio-economic influences on fuel poverty using household fuel spend data: A meso-scale study in Scotland, Indoor Built Environ. 2017, 1-23.

[24] R. Walker, H. Thomson, C. Liddell, Fuel Poverty 1991-2012: Commemorating 21 Years of Action, Policy and Research, University of Ulster \& University of York, 2013.

[25] Department for Energy and Climate Change, Green Deal and Energy Company Obligation (ECO): Monthly Statistics, 2015, Department for Energy and Climate Change, London, (Available at:

https://www.gov.uk/government/statistics/green-deal-and-energy-company-obligation-eco-monthly-statisticsaugust-2015 (Last accessed 17 January 2018).

[26] Affinity Sutton, FutureFit: Final Report Part 2, July 2013, Available at: http://www.affinitysutton.com/media/364652/futurefit-quick-links-PDF-1.pdf (Last accessed 13 March 2018).

[27] K.J. Baker, R. Emmanuel, M. Phillipson, Support for RPP2 - Housing Futures, 2012. Report for

ClimateXChange Scotland, 2012, Available at: http://www.scotland.gov.uk/Resource/0038/00389071.pdf (Llast accessed 13 March 2018).

[28] K. Beckmann, S. Roaf., S., Workshop Report: Climate Resilience for the Scottish Built Environment, 2013, Report for ClimateXChange Scotland, Available at:

http://www.climatexchange.org.uk/files/6113/7356/2210/CXC_Built_Env_EnablEnv_WorkshopRecommendati onsReport.pdf (Last accessed 13 March 2018).

[29] Consumer Focus Scotland, Consumer Focus Scotland's response to the Scottish Government Building Standards Division Consultations on: Section 63: Energy Performance of Non-Domestic Buildings; and Energy Performance of Building Directive - Recast, 2012, Consumer Focus Scotland (Available at:

http://www.consumerfocus.org.uk/scotland/files/2012/01/Consumer-Focus-Scotland-response-to-SG-BuildingStds-Consultations.pdf (Last accessed 13/03/18).

[30] Jones Lang LaSalle, A Tale of Two Buildings: Are EPCs a True Indicator of Energy Efficiency?, 2012, Better Buildings Partnership. Available at: http://www.betterbuildingspartnership.co.uk/download/bbp-jll---atale-of-two-buildings-2012.pdf (Last accessed 13 March 2018].

[31] C. Sanders, M. Phillipson, Review of Differences between Measured and Theoretical Energy Savings for Insulation Measures, 2006, Department for the Environment, Food and Rural Affairs (Defra), London, UK, Available at:

http://www.decc.gov.uk/assets/decc/what\%20we\%20do/supporting\%20consumers/saving_energy/analysis/insul ationmeasures-review.pdf (Last accessed 17 October 2017).

[32] UK Green Buildings Council, Zero-Carbon Non-Domestic Buildings, 2010, UK Green Building Council (March 2010).

[33] I.G. Hamilton, P.J. Steadman, H.R. Bruhns, A.J. Summerfield, R. Lowe, Energy efficiency in the British housing stock: energy demand and the Homes Energy Efficiency Database, Energy Policy 60, 2013, 462-480. [34] A.J. Summerfield, R.J. Lowe, H.R. Bruhns, J.R. Caeiro, J.P. Steadman, T. Oreszcyn, Milton Keynes Energy Park revisited: changes in temperatures and energy usage, Energy Build. 37, (7), 2007, 783-791.

[35] K.J. Baker, Renewable Heat: The perfect storm?, (2017) In G. Wood, K.J. Baker, (Eds), A Critical Review of Scottish Renewable and Low Carbon Energy Policy, Palgrave Macmillan, 81-102, (August 2017).

[36] Centre for Sustainable Energy, Beyond Average Consumption: Development of a Framework for Assessing Impact of Policy Proposals on Different Consumer Groups, 2014, Report for the Office of Gas and Electricity Markets (Ofgem), UK, Available at:

https://www.ofgem.gov.uk/sites/default/files/docs/2014/06/cse_14 beyond_average_consumption_report_to_of gem_march_2014_update.pdf (Last accessed 03 April 2018).

[37] Scottish Government, Home Energy Efficiency programmes for Scotland: Summary Delivery Report 2015/16, 2017, Available at: http://www.gov.scot/Publications/2017/08/6419/0 (Last accessed 13 March 2018). [38] Energy Saving Trust, Centre for Sustainable Energy, \& National Energy Action, Warm Zones Evaluation: Final Report, 2005, Available at: https://www.cse.org.uk/downloads/reports-and-publications/policy/insulationand-heating/warm_zones_external_evaluation_exec_summary.pdf (Last accessed 13 March 2018).

[39] B. Boardman, S. Darby, S., Effective Advice: Energy Efficiency and the Disadvantaged, 2000, Environmental Change Institute, University of Oxford, UK. 
[40] Google Dictionary, Customer, 2019. Available at: https://www.google.com/search?rlz=1C1CHBF_enGBGB803GB803\&q=Dictionary\#dobs=customer (Last accessed 23 January 2019).

[41] Google Dictionary, Client, 2019. Available at: https://www.google.com/search?rlz=1C1CHBF_enGBGB803GB803\&q=Dictionary\#dobs=client (Last accessed 23 January 2019).

[42] Scottish Government, 2008. Public Value and Participation: A Literature Review for the Scottish Government.

[43] J. Mackinnon, M. Reid, M., A. Kearns, Communities and Health Improvement: A Review of Evidence and Approaches, 2006, Report for Health Scotland. Department of Urban Studies, University of Glasgow.

[44] J. Morris, Removing the Barriers to Participation, 2006, Report for the Institute for Public Policy Research (IPPR) and the National Community Forum, London.

[45] S. Roaf, K.J. Baker, A. Peacock, Evidence on Hard to Treat Properties, 2008, Report for the Scottish Government, Available at: http://www.gov.scot/Publications/2008/10/17095821/0 (Last accessed 13 March 2018).

[46] J. Stearn, Consumer vulnerability is market failure, 2016, In K. Hamilton, S. Dunnett, M. Piacentini, (Eds), Consumer Vulnerability: Conditions, Contexts and Characteristics, Routledge (2016).

[47] International Standards Organisation, ISO 26000:2010 - Guidance on Social Responsibility, 2010,

Available at: https://www.iso.org/obp/ui/\#iso:std:iso:26000:ed-1:v1:en (Last accessed 16 June 2018).

[48] J. W. Schooler, S. Ohlsson, K. Brooks, K., Thoughts Beyond Words: When Language Overshadows Insight, J. Exp. Psych. General, 122, (2), 1993, 166-183.

[49] P.B. Ainsworth, Turning Heroes into Villains: The Role of Unconscious Transference in Media Crime Reporting, 1998, In J. Baros, I. Munnich, M. Szegedi, (Eds), Psychology and criminal justice: International review of theory and practice, De Grutyer, 399-406, (1998).

[50] K.J. Baker, Hidden Geographies of Fuel Poverty: Going beyond a conventional approach, 2017,

Presentation to the Holyrood Conferences conference on on Eradicating Fuel Poverty: Delivering Warm Homes, Edinburgh, (March 2017), Available at: http://www.energypovertyresearch.org (Last accessed 23 January 2019). [51] R. Walker, C. Liddell, P. McKenzie, C. Morris, S. Lagdon, Fuel poverty in Northern Ireland: humanizing the plight of vulnerable households, Energy Res. Soc. Sci. 4, 2014, 89-99.

[52] N. Denzin, Sociological Methods: A Sourcebook, 5th edition, Aldine Transaction, 2006, ISBN 9780202308401 .

[53] M. Green, Voices of People Experiencing Poverty in Scotland: Everyone Matters?, 2007, Poverty Alliance, Joseph Rowntree Foundation, UK.

[54] Triangulation in Social Research: Qualitative and Quantitative Methods can really be Mixed, 2004, In:

W.K. Olsen, M. Holborn, U. Haralambos (Eds.), Developments in Sociology, Causeway Press.

[55] M.Q. Patton, Qualitative Evaluation and Research Methods, 1990, SAGE Publications, Newbury Park, UK.

[56] P. Rothbauer, Triangulation, 2008, In: L. Given (Ed.), The SAGE Encyclopedia of Qualitative Research

Methods, 892-894, Sage Publications.

[57] Ofgem, Carbon Emissions Reduction Target ('CERT') Super Priority Group:

Suppliers' Proposal for 'SPG Percentage, 2012, Office of Gas and Electricity Markets (Ofgem), UK, (29

October 2012. Available at: https://www.ofgem.gov.uk/publications-and-updates/carbon-emissions-reductiontarget-cert-super-prioritygroup-suppliers-proposal-spg-percentage (Last accessed 26 February 2018).

[58] M. Rojas, Well-being and the Complexity of Poverty: A Subjective Well-being Approach, 2004, Research Paper, UNU-WIDER, United Nations University (UNU) 2004/29, Available at:

https://www.econstor.eu/handle/10419/63558 [last accessed 13 March 2018).

[59] L. Middlemiss, R. Gillard, Fuel Poverty from the Bottom-up: Characterising Household Energy

Vulnerability through the Lived Experience of the Fuel Poor, Energy Res. Soc. Sci. 6, 2015, 146-154.

[60] J. Speirs, New Perspectives on Vulnerability using Emic and Etic Approaches, J. Adv. Nurs. 31 (3), 2000, 715-721.

[61] S.C. Dwyer, J.L. Buckle, The Space Between: On Being an Insider-Outsider in Qualitative Research, J. Qual. Method. 8 (1), 2009, 54-63.

[62] R. Evered, M. Reis Louis, M., Alternative Prospective in the Organizational Sciences: Inquiry from the Inside and Inquiry from the Outside, Acad. Manage. Rev. 6 (3), 2001, 385-395.

[63] C. Kottak, Mirror for Humanity, McGraw Hill, New York, 2006, ISBN 978-0-07-803490-9.

[64] J.L. Olive, Reflecting on the Tensions Between Emic and Etic Perspectives in Life History Research: Lessons Learned, Forum Qualitative Sozialforschung / Forum, Qual. Soc. Res. 15 (2), 2014.

[65] J. Maltby, G. Williams, J. McGarry, L. Day, Research Methods for Nursing and Healthcare, Pearson Education, Harlow, 2010, ISBN 9780273739678.

[66] S.L. Schensul, J.J. Schensul, M.D. LeCompte, Essential ethnographic methods, Observations, Interviews and Questionnaires Vol. 2, Rowan Altamira, 1999, ISBN 9780759122017. 
[67] National Archives, Data Protection Act 1998, 1998, Available at: www.legislation.gov.uk/ukpga/1998/29/contents (Last accessed 17October 2017).

[68] National Archives, Welfare Reform Act 2012, 2012, Available at:

www.legislation.gov.uk/ukpga/2012/5/contents/enacted/data.htm (Last accessed 17 October 2017).

[69] National Records of Scotland, Household Composition for Specific Groups of People in Scotland:

Scotland's Census 2011, 2015, Office of National Statistics, UK, Available at:

http://www.scotlandscensus.gov.uk/documents/analytical_reports/HH\%20report.pdf (Last accessed 08 March

18).

[70] Scottish Government, The Energy Efficiency Standard for Social Housing (EESSH) - Scottish Government Guidance for Social Landlords (Revised December 2017), 2017, Available at:

http://www.gov.scot/Publications/2017/12/2678/0 (Last accessed 15 March 2018).

[71] Scottish Government, Scottish House Condition Survey, 2018, Available at:

http://www.gov.scot/Topics/Statistics/SHCS (Last accessed 15 March 18).

[72] Scottish Government, Community Empowerment and Engagement, 2015, Available at:

http://www.gov.scot/Topics/People/engage (Last accessed 08 October 17).

[73] Scottish Government, A Connected Scotland: Tackling Social Isolation and Loneliness and Building

Stronger Communities, 2018, Available at: http://www.gov.scot/Publications/2018/01/2761 (Last accessed 03

April 18).

[74] A.S. Reber, Implicit Learning and Tacit Knowledge, 1989, J. Exp. Psych. General, 118 (3), 1989, $219-235$.

[75] M.J. Grubb, Energy Efficiency and Economic Fallacies, 1990, Energy Policy, 18, 783-785.

[76] B. Castellani, Complexity and the Failure of Quantitative Social Science, Discover Society, November 2014, Available at: http://discoversociety.org/2014/11/04/focus-complexity-and-the-failure-of-quantitativesocial-

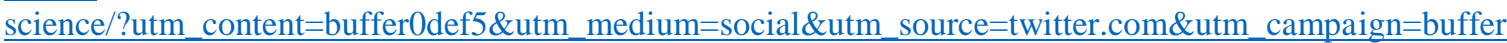
(Last accessed 23 February 2018).

[77] A. Reeves, Exploring Local and Community Capacity to Reduce Fuel Poverty: The Case of Home Energy Advice Visits in the UK, 2016, Energies, Available at: http://www.mdpi.com/1996-1073/9/4/276/pdf (Last accessed 03 March 2018).

[78] Energy Saving Trust, Centre for Sustainable Energy, National Energy Action, Warm Zones Evaluation: Final Report, 2005, Available at: https://www.cse.org.uk/downloads/reports-and-publications/policy/insulationand-heating/warm_zones_evaluation_full_final.pdf (Last accessed 16 March 2018).

[79] J. Green, S. Darby, C. Maby, B. Boardman, Advice into Action: An Evaluation of the Effectiveness of Energy Advice to Low Income Households, 1998, Report for the Eaga Charitable Trust, UK.

[80] R. Parnell, O. Popovic Larsen, Informing the Development of Domestic Energy Efficiency Initiatives: An Everyday Householder-centred Approach, 2005, Environ. Behaviour, 37 (6), 787-807.

[81] R. Emmanuel, K.J. Baker, K.J., Carbon Management in the Built Environment, 2012, Routledge. [82] Scottish Government, Fuel Poverty (Target, Definition and Strategy) (Scotland) Bill, 2018, Available at: https://www.parliament.scot/parliamentarybusiness/Bills/108916.aspx (Last accessed 04 January 2019).

[83] K.J. Baker, R. Mould, Energy Performance Certificates: An Alternative Approach, 2019, Policy paper for Common Weal, Scotland, Available at: http://allofusfirst.org/library/energy-performance-certificates-analternative-approach/ (Last accessed 04 January 2019). 